\title{
Breaking the Cycle of Continued Evolution Education Controversy: On the Need to Strengthen Elementary Level Teaching of Evolution
}

\author{
Ronald S. Hermann
}

Published online: 16 March 2011

(C) Springer Science+Business Media, LLC 2011

Evolution education in the United States is a contentious issue as evidenced by the low number of Americans who accept evolution. Miller et al. (2006) reported on survey results indicating that, compared to European countries, America was second to last in acceptance of evolution. Given such a low acceptance rate, it logically follows that evolution may not be well understood by Americans. In recent years it has become exceedingly clear that students maintain a dismal understanding of evolution (Demastes et al. 1995; Deniz et al. 2008; Lawson and Worsnop 1992; Lord and Marino 1993; Sinclair and Pendarvis 1997). Indeed, Moore and Cotner (2009) reported that despite evolution being a required part of the high school curriculum in most states, college students scored an average of $54 \%$ on the Knowledge of Evolution Exam as measured prior to taking an introductory biology course. Without question, scientifically educated citizens should understand evolutionary theory given the fact that the modern theory of evolution undergirds other areas of science research ranging from genetics to anatomy to ecology. The accrued evolution education research, however, suggests evolution is poorly understood despite a diverse list of scientific and religious organizations that support the teaching of evolution based on the premise that evolution is the best scientific explanation for the origin of species (Sager 2008). With such a diverse and expansive list of evolution supporters, the question remains as to why those exposed to evolution education do not generally demonstrate mastery of the concept.

\section{R. S. Hermann $(\bowtie)$}

Towson University,

8000 York Road,

Towson, MD 21253, USA

e-mail: rhermann@towson.edu
The fact that understanding of evolutionary theory is low has resulted in religious beliefs portrayed as negatively influencing one's understanding of evolution. However, there is evidence that the conflict model of science and religion, is an oversimplification of the issue. For example, Colburn and Henriques (2006) found that much of the clergy is supportive of evolution instruction, and The Clergy Letter Project (http://www.butler.edu/ clergyproject/rel_evol_sun.htm) has obtained over 12,000 letters from Christian, Judaism, and Unitarian Universalist clergy supporting the teaching of evolution. On the other hand, Moore (2004) indicated that as much as $60 \%$ of the 103 Minnesota science teachers he surveyed made procreationist comments, and Berkman et al. (2008) reported that one-sixth of biology teachers are young-Earth creationists. The boundaries between who accepts and who rejects evolution are blurred. Research suggests that students may be confused about the interaction between science and religion and many may be reluctant to learn evolutionary theory if they perceive a conflict with their religious beliefs (Brazelton et al. 1999; Esbenshade 1993). Often, the perceived contentious nature of evolution education is evident in the science classroom as students and parents express concern with the teaching of evolutionary concepts. As a result, evolution educators are given the difficult task of educating all students, when some students are reluctant learners of evolution. The manner in which these teachers address evolution is critical (Donnelly and Akerson 2008; Hermann 2008). There is no doubt that the approach that high school biology teachers take to deliver evolution instruction impacts the learning of evolution and students' attitudes toward evolution. Equally important, however, is the collective science education students receive prior to their earliest evolution learning experience. The purpose of the present 
paper is to suggest that the experiences children have prior to their earliest evolution learning experience are equally, if not more, important experiences for developing an understanding and acceptance of evolution. Furthermore, this paper serves as a call to action for science educators to work toward the development of elementary pre-service science education programs that yield teachers knowledgeable about evolutionary theory and related pedagogical content knowledge.

\section{The Cycle of Continued Evolution Education Controversy}

There are numerous complex and intimately intertwined factors that have resulted in the low understanding and acceptance of evolution in the United States. Political, religious, social, and educational influences have resulted in the perception that evolution is a controversial topic. While not a controversial scientific topic, within the cultural conversation evolution is viewed as a controversial topic (Hermann 2008). As such, the diverse societal influence on young learners of evolution can be dramatic, especially when magnified by media sources covering challenges to the teaching of evolution. An argument could be made that the combined effect of societal factors, including the media, has led to a general portrayal of science and religion in conflict with one another. Many children probably hear opinions and information about evolution, or religious explanations of the same phenomenon, during their developing years and well into their formal science schooling. For a subset of students, belief in evolution is not congruent with their belief system, and such students resist learning about the intricacies of the theory and the supporting evidence across diverse scientific disciplines. Some learners and their families are so resistant that they initiate challenges to the teaching of evolution in public schools across the nation. Since the infamous Scopes trial in 1925, the number of challenges to the teaching of evolution has increased in frequency, suggesting that supporters of evolution have failed to win the hearts and minds of all students who pass through our science classrooms. One result is that alienated students may reject evolution and pass similar views on to their children. Thus, a vicious and repetitive cycle of continued evolution education controversy continues with increasing momentum. It is becoming even clearer that present approaches to teaching evolution have not had the desired results, and reformed pedagogical approaches to the teaching of evolution are desperately needed to break the cycle of the continued evolution education controversy.

\section{Breaking the Cycle}

From a pragmatic stance, there are two primary approaches science educators can take to break the cycle of continued evolution controversy. The first approach is to develop effective strategies for teaching evolution in a manner that does not alienate resistant students. This approach is mainly limited to the high school biology classroom. The second approach is to provide a comprehensive pathway that provides a framework for understanding evolution prior to high school biology, or students' earliest evolution learning experience. Here, I show the challenges to the first approach and evidence supporting the notion that it is beneficial to invest time and energy in the latter approach. Furthermore, a review of both approaches provides critical insight into the development of students' views on evolution and how science educators can foster the development of positive views on evolution.

\section{High School Evolution Experiences}

As evidenced by the generally low understanding of evolution held by students, either learning evolution has proven to be a challenging topic for many students or many students are reluctant to learn evolution. Even for those students who may be willing and able to learn evolution, several barriers remain. Students often may only be exposed to evolutionary theory once during their formal education, typically in their high school biology class. Unfortunately, that experience is often limited in scope and depth of coverage. Berkman et al. (2008) recently reported that of the 939 teachers surveyed, $17 \%$ did not cover human evolution and $2 \%$ did not cover general evolutionary processes. In light of the fact that evolution is widely considered to be a unifying theme in biology, it is staggering that the survey also revealed that $36 \%$ of teachers spent less than six hours of coverage on general evolutionary processes. The lack of evolution content covered in the biology classroom is exacerbated by the aforementioned research indicating that many biology teachers maintain creationist views. Moore and Cotner (2009) reported that students in biology courses that included creationism or excluded both creationism and evolution were associated with students knowing less about evolution when tested at the college level. Thus, it is quite plausible that many students receive inadequate evolution education at the high school level. Unfortunately, there is a dearth of studies exploring high school students' experiences with evolution education. Thus, much of what can be said about high school evolution education is based on studies conducted at the postsecondary level. The lack of secondary evolution education studies may be due to difficulties receiving approval by Institutional Review Boards at universities or within 
school systems, or may be due to the preference of university researchers to use a convenient sample of students on campus. Here, results from post-secondary studies are utilized to provide insight into the views the secondary student is likely to maintain as well.

Whether because of limited exposure to evolution content, conflicting religious views, or some other mechanism, students enter college with a limited understanding of evolution. In a study of 392 university students, Lord and Marino (1993) reported that only $7.1 \%$ of the students polled thought that evolution occurred because individuals better fit for the environment had a greater potential to leave a larger number of offspring, while the remainder selected misconceptions such as the purposeful striving toward higher forms $(42.4 \%)$. Given the fact that the question measured student understanding of a fundamental principle of biological evolution, the data strongly suggest that students enter college lacking the foundational understanding of one of biology's most overarching theories.

Even with specific interventions designed to address misunderstandings or provide depth of content, understanding of evolution remains generally low. Perhaps the most significant report of student understanding comes from the seminal work of Bishop and Anderson (1990), who used principles of conceptual change learning to force dissatisfaction with existing conceptions in an attempt to increase scientific understanding. They studied 110 college students enrolled in non-majors' introductory biology and identified three major ways that student conceptions differed from scientific conceptions. Students believed that the environment, rather than random processes and natural selection, causes traits to change over time. Students maintained naïve conceptions, often Lamarckian in nature, and did not view the variation within a population as important to evolution. Finally, students viewed evolution as a gradual change in the traits themselves (traits either improving or deteriorating from one generation to the next) rather than a change in the proportion of individuals in a population. The researchers also noted that students confused terminology, namely the terms "adapt" and "fitness" were used in an everyday language sense rather than within a scientific context of evolution. Their results also showed that previous biology instruction had little or no effect on student conceptions. Most strikingly, only $31 \%$ of students with two or more previous years of biology instruction demonstrated an understanding of any scientific conception of evolution. These findings suggest that many students are resistant to learning evolutionary concepts and that understanding is likely to increase only minimally after concerted efforts to address misconceptions.

Scharmann (1990) reported on a diversified instructional lesson in which two groups of non-major general biology students were compared with one group receiving an intervention. No significant differences for understanding of evolutionary content items were found, but there were significant differences for understanding of the nature of scientific theory and attitude toward evolution $(U=1.75$; $p<0.05$ ). Again, the lack of increased understanding of evolution suggests that prior experiences may limit student willingness, or ability, to understand evolution.

Even among biology majors, understanding of evolution remains low. Sinclair and Pendarvis (1997) surveyed 218 introductory college zoology students using an inventory containing 12 multiple choice items and four open-ended questions. They found that only $21.2 \%$ on the pretest and $33.9 \%$ on the post-test demonstrated an understanding of Darwinian evolution. Most of the students selected more Lamarckian explanations, such as, organs and structures that are not needed are lost.

Some researchers have developed interventions specifically designed to address well-documented misconceptions of evolutionary theory, although their findings generally indicate that while gains can be made as a result of the intervention, the post-test scores remain unacceptably low. Jensen and Finley (1995) used conceptual change instruction in conjunction with the use of historical materials to teach evolution to 42 students. Students were able to answer questions about evolution better after the intervention $(t=8.76, \mathrm{df}=40$, alpha $=0.005)$; however, the researchers reported two problems. First, students were still answering fewer than $50 \%$ of all questions in Darwinian terms after instruction, and second, a number of items remained difficult for students to understand. This data suggests that conceptual change strategies, despite directly targeting misconceptions, cannot overcome students' prior conceptions of evolutionary concepts.

In another intervention, a historically rich curriculum and paired problem solving approach was reported by Jensen and Finley (1997) to increase understanding. Evaluation of preand post-test results showed an increased use of Darwinian ideas and a decreased use of non-Darwinian ideas, although non-Darwinian ideas were not totally eradicated from students' responses. Despite the intervention, students maintain the misconceptions they developed over the years prior to their formal evolution education.

Recently, Moore and Cotner (2009) reported that students' high school experiences in biology have a greater impact on their acceptance of evolution than an introductory level college biology course. By experiences, the authors refer to the extent to which the students' biology teachers included creationism in their biology courses. They found that inclusion of creationism significantly increases the probability of students accepting creationism and rejecting evolution. Thus, students exposed to evolution (and not creationism) should be more accepting of evolution. This finding is promising, but the extant 
literature described above suggests that students generally do not possess a strong command of evolutionary concepts when they enter college. Furthermore, Paz-y-Mino and Espinosa (2009) recently suggested that biology majors are more accepting of evolution than non-majors and that acceptance of evolution increased with academic level within the 476 college biology majors surveyed. Some studies suggest there is not a relationship between acceptance of evolution and understanding of evolution (Bishop and Anderson 1990; Demastes et al. 1995; Lord and Marino 1993; Sinatra et al. 2003), while others suggest such a relationship may exist (Deniz et al. 2008; Johnston and Peeples 1987; Rutledge and Warden 2000). Whether or not there is a relationship between acceptance and understanding of evolution, this data clearly indicates the need for evolution to be taught at all levels, including prior to high school, if only to increase the level of acceptance of evolution to be on par with European countries (see Miller et al. 2006).

What these reports have indicated is that interventions of various designs fail to have large enduring effects in terms of increasing students' understanding of evolutionary concepts. When gains are made, post-test scores are still generally below acceptable levels of understanding, i.e., failing grades. Furthermore, given the fact that the studies were conducted with college students, they provide little evidence that evolution at the secondary level or postsecondary level contributes to an enduring knowledge of evolutionary concepts. There is reason to believe that interventions at the high school level or earlier can provide significant gains in understanding. Beardsley (2004) conducted a study of eighth grade students and found that an intervention consisting of inquiry-based activities and historically rich curricular material significantly improved student learning of evolution. Despite this finding, Beardsely concluded that "one-shot attempts to instill an understanding have proven to be insufficient in helping most students achieve a working knowledge of evolution by natural selection" (p. 610). This key finding supports the thesis of this paper that a sequential, systemic approach to teaching evolution is needed beginning in elementary school and middle school.

There is no doubt that the aforementioned studies provide desperately needed insight into the types of instructional practices that produce the most positive gains in understanding of evolution. They also suggest, however, that despite the strategic planning and implementation of lessons specifically designed to increase understanding of evolution, students show very little gain in understanding of evolutionary concepts during their secondary and post-secondary educational experiences. Thus, the sum total of a child's life experiences preceding their earliest evolution learning experience may contribute to the inability to fully understand evolution at the secondary and post-secondary level.
Pre-high School Evolution Experiences

Given the extant literature regarding students' inability, or unwillingness, to learn about evolution, it is reasonable to suggest that the confluence of events that occur during adolescence coalesce to shape students' ideas about evolution. In a study of students' earliest evolution learning experience, Donnelly and Akerson (2008) conclude that students are clearly being exposed to evolution prior to high school with experiences occurring during their elementary school years in the context of school, home, religious, and media exposure. Given the low percentage of Americans who accept evolution, and the number of science teachers who support creationism or intelligent design, it is clear that many children are exposed to anti-evolution sentiments during adolescence. Lombrozo et al. (2008) stated that there is a critical need for children to develop an understanding of science so that they can evaluate anti-evolution messages when first encountered. One explanation for the low understanding of evolution among students is that they were not exposed to the nature of science and sufficient science content knowledge and, therefore, did not understand science as a way of knowing about the world well enough to critically evaluate the anti-evolution messages that they were exposed to prior to high school. By reviewing some of the literature from developmental psychology and science education research, the science education community can identify salient aspects of a comprehensive pre-high school curriculum for developing an understanding of evolution for all science students. One purpose of the present paper is to describe the need for a focused research agenda on the experiences, formal and informal, that may influence students' views of evolution later in their formal science instruction at school. Relatively little is known about the formation of students' views of evolution, though much research has focused on describing students' views and measuring their understanding of evolution during their high school or college years. Science education researchers would be well served to investigate the development of student views in addition to describing those views. We may not be satisfied with the descriptions of secondary student views, but we may be able to alter the development of student views if we do so prior to secondary school biology. There remain several questions that are central to understanding the development of students' views on evolution and the role science educators can play in the development of views that are commensurate with those of the scientific community. What factors contribute to the development of students' views? What can science educators do to facilitate the development of students' views? To what extent can science educators develop positive views toward evolution if external factors exert a negative influence on children's views? The extant 
literature in several domains provides critical insight into addressing questions regarding the factors that influence the development of students' views of evolution.

\section{Developmental Factors}

Deniz et al. (2008) suggest that affective and contextual factors play a role in forming one's conceptual ecology and these factors must be considered during instruction. The researchers provide examples of these factors such as reasoning level, religious perspective, views of science and the nature of science, thinking dispositions, and epistemological beliefs. Having identified these factors, science educators can provide experiences to strengthen students' scientific worldview perspective. For example, Lombrozo et al. (2008) provide some characteristics of the nature of science that may be beneficial in facilitating an understanding of evolution by way of an increased understanding of the nature of science such as that (1) scientific theories are trustworthy and reliable but require provisions, (2) in order to test a theory additional theories are needed, and (3) there are multiple scientific methods employed by scientists. These characteristics should be well understood prior to exposure to high school evolution content; however, Dodick and Orion (2003) indicate that nature of science (NOS) is often not emphasized in science classrooms.

Adding credence to the claim that early childhood science experiences are critical to shaping young students' views of evolution, Bloom and Weisberg (2007) find that the primary source of resistance to evolution instruction is related to what children know before their exposure to science. Bloom and Weisberg (2007) assert that resistance to scientific claims will persist into adulthood if those claims are contested in society, and the resistance will be especially strong "if there is a nonscientific alternative that is rooted in common sense and championed by people who are thought of as reliable and trustworthy" (p. 997). This finding is disconcerting, considering the report by Moore and Cotner (2009) stating that $20-40 \%$ of U.S. biology teachers include creationism in their classes or omit evolution all together. These teachers will be viewed as reliable and trustworthy by students, and the creationist ideas they present tend to be commonsense ideas for many people. Science educators cannot be expected to directly affect the nonscientific alternatives to evolution that are propagated outside the classroom. The cultural conversation regarding evolution largely takes place outside the classroom, and science teachers cannot be expected to challenge the authority figures in a young child's life who may be facilitating the development of views that run counter to those of proponents of evolution. Authority figures-mainly parents-can have a great influence on the development of a child's views on evolution. Therefore, it is imperative that elementary teachers foster the development of a strong understanding of the nature of science, skills and processes of science, and the fundamental science concepts that support the learning of evolutionary theory. But what factors influence the development of students' views about evolution?

In a series of studies among children aged five to 12 years, Evans (2000) concluded that eight to nine-year-old children were likely to opt for creationist beliefs regardless of parental beliefs. However, preadolescents who had evolutionist parents, were more likely to be strongly evolutionist themselves. Children aged 10 to 12 years were able to provide evolutionary explanations, although those explanations were likely to be Lamarckian rather than Darwinian in nature. Evans' findings are supported by Shtulman (2006) who suggested that cognitive development within an individual often parallels the historical progression of scientific thought as more evidence comes to light. Thus, teaching about the historical development of current evolutionary theory is a beneficial approach to teaching about the history of science within the context of evolution and should be taught prior to high school biology.

Evans' (2001) study of 185 children and their mothers $(n=92)$ indicates that not until their early adolescent years (11 to 13 years) were children ready to abandon creationist theories and adopt naturalistic explanations that violated their strongly held beliefs. Evans (2001) hypothesizes that parental beliefs in evolution facilitate this shift directly by explicitly endorsing evolution and exposing children to evidence for evolution, such as fossils, and indirectly by promoting naturalistic interests in general. Furthermore, Evans (2000) finds that preadolescents' fossil knowledge appears to block the effect of parental creationist beliefs on preadolescents' expression of creationism, suggesting that early formal education can counteract some antievolution experiences. This finding is promising because it suggests that an understanding of science content supporting evolutionary theory may offset some of the anti-evolution messages young children are susceptible to in their formative years.

It is clear that our task of ensuring a valid science education remains to be completed. Comprehensive exposure to the habits of mind and the skills and processes that undergird evolution instruction are crucial to breaking the cycle of persistent challenges to evolution education. Only by providing consistent exposure to the processes of science can evolution also be viewed as a commonsense theory. Students must have a firm understanding of how and why science is conducted, and the skills and processes of science must be viewed as being as important as the science content found within state curricula. Fail (2008) makes a compelling argument for including biological principles of evolution usually reserved for high school 
students in our teaching of elementary students since evolutionary theory provides a cohesive and connected storyline that ties together many other life science concepts.

Science educators cannot dictate the exposure to evolution education students receive outside of school. The attitudes of parents, family members, clergy, and the general public and media are, for all intents and purposes, beyond the scope of science educators. The way in which these groups talk about evolution is a critical element in facilitating the development of students' views on evolution. In a series of three experiments, Harris et al. (2006) sought to determine which entities (e.g., the tooth fairy, witches, flying pigs, germs, oxygen) children aged four to eight years thought existed and on what basis they made the claim for existence. Since direct observation of the entities examined is not possible, the researchers explored the role of other peoples' testimony about the entities. Harris et al. (2006) found that “children's beliefs vary with the level of testimonial support that they encounter, particularly from trusted sources such as parents" (p. 93). Given this finding, it is of critical importance that elementary and middle school science teachers discuss evolution with a common vernacular that provides positive testimony for evolution. Evolution should be included in the science curriculum beginning in elementary school, and some ideas of pedagogical approaches appear later in this paper (Asghar et al. 2007; Chanet and Lusignan 2009; Fail 2008). Furthermore, the skills and processes of science should be covered with sufficient depth, beginning in primary school. For example, theories and hypotheses should be discussed in a consistent manner so that students fully understand the power of a theory prior to high school. Understanding of the nature of science is critical as students' misunderstandings of the nature of science are used to dismiss evolutionary theory (Dagher and Boujaoude 2005). Instruction on the nature of science is imperative for primary grades. Young children are developing ideas about the world and may not readily distinguish between believing and knowing, thereby leading to a greater difficulty distinguishing between science and non-science.

Undoubtedly, the role elementary teachers play in directly or indirectly facilitating an understanding and acceptance of evolution is paramount. They can directly facilitate an understanding and acceptance of evolution by teaching aspects of evolution that are grade-level appropriate, considering that cognitive development of elementary level students may preclude many from fully appreciating the intricacies of the theory. Some recently reported studies indicated that foundational concepts of evolution can successfully be taught to elementary students. Chanet and Lusignan (2009) provided details on the teaching of some aspects of evolution that are taught in France such as animal classification, interrelationship trees, and a comparison of natural selection to intelligent design. In a study conducted in the United States, Nadelson et al. (2009) developed and taught lessons on speciation and adaptation to kindergarten and second-grade students using inquiry and modeling. They concluded that the lessons were successful as students were able to communicate an understanding of similarities and differences of forearm structures. Directly teaching foundational concepts that provide concrete schema, further enabling sufficient scaffolding, is essential for the development of a more sophisticated understanding of evolution as science instruction continues in subsequent grades. Just as directly teaching foundational evolutionary concepts is critical, so too is teaching concepts, skills, and processes that support and undergird the teaching of evolution.

By directly teaching about evolution, elementary teachers may further students' understanding of the basic mechanisms and ideas that will more thoroughly be presented in later years. Elementary teachers, however, will likely need specialized training in this area, and even with that training, they may be reluctant or unable to teach evolution. Ashgar et al. (2007) report that among the Canadian pre-service elementary teachers in their study, most lacked an understanding of even the most basic concepts of evolution, and almost a third planned to avoid or had reservations about teaching evolution. This report is troubling considering the context of the study. The authors explain that in the Canadian province where the study was conducted, the province-wide elementary science curriculum mandates the teaching of evolution. Further, the pre-service teachers in the study had recently completed a course in which evolution was addressed. The fact that a third of pre-service teachers did not accept evolution after they were exposed to evolutionary concepts through lectures, laboratory exercises, videos, discussions, visits to a natural history museum, and assignments focusing on various fossil specimens suggests that simply teaching more about evolution does not change students' views of evolution. Perhaps the addition of an exploration into the differences between evolution and creationism may facilitate a shift in students' views of evolution. Helgeson et al. (2002) reported that many of the 48 pre-service elementary education majors who participated in a mock trial regarding a sixth grade teacher fired for not balancing evolution and creationism changed their views in favor of teaching evolution at the expense of creationism. Together these reports indicate the need for a concerted effort to prepare elementary teachers to teach evolution and some insight into the types of activities that may facilitate an understanding and acceptance of evolutionary theory.

Science teachers must also indirectly facilitate an understanding and acceptance of evolution by teaching about the difference between believing and knowing, the methods of science; and the development of experimental 
designs as compared to non-experimental designs, fossil evidence related to the age of the earth, and the manner in which strata provide evidence for evolution, among a host of other activities that generally support evolutionary concepts.

By teaching about the nature of science during the elementary years, elementary teachers may provide some of the necessary information needed for students to critically analyze both evolution and anti-evolution information.

\section{Conclusions}

The science education that children receive prior to high school biology may be as important, or more important, to shaping the hearts and minds of students. Acceptance of evolution, understanding of evolution and/or rejection of intelligent design are largely determined prior to high school biology for many students. There is promising evidence that early evolution instruction, along with NOS instruction, can compensate for the anti-evolution testimony children hear from parents, clergy, politicians, teachers, media, etc. Evolution education is contextual and transcends cognitive and affective domains. Thus, the journey to understanding evolution is long, and influences come from many diverse people with a variety of agendas and worldviews. To compensate for the anti-evolution exposure children receive prior to high school, a comprehensive pathway to understanding evolution and the nature of science is needed within the pre-high school curriculum. Though such a pathway may exist on paper, clearly the extent to which it is enacted is called into question by much of the extant literature. Recently, the need for a curriculum including evolution education for elementary students has been advocated by several science educators. Eldredge and Eldredge (2009) suggest a universal evolutionary curriculum for K-16 students containing several modules that can be modified to fit specific grade levels and local curricular needs. Similarly, Wagler (2010) presents potential K-4 biological evolution standards to be used in conjunction with National Science Education Standards that currently lack K-4 evolution content standards.

There is a lack of science education research exploring the development of students' views of evolution. The present paper serves as a call to action for a focused prehigh school evolution education curriculum and the initiation of a dialogue on what such an enacted curriculum should entail. While there is a need for further research regarding the teaching of evolution and the nature of science during primary school, there is evidence that the science education community should put its energy and resources into gaining insight into the types of interactions youngsters have with evolution prior to high school biology. High school and college students continue to show little understanding of evolution. Myriad approaches to teaching evolution have been described with little improvement in understanding of evolution. The experiences students have inside and outside of the classroom may affect their ability or desire to understand evolution. Thus, adequate and exhaustive coverage of evolution and the nature of science needs to begin during the primary grades.

\section{References}

Asghar A, Wiles JR, Alters B. Canadian pre-service elementary teachers' conceptions of biological evolution and evolution education. McGill J Educ. 2007;42(2):189-209.

Beardsley PM. Middle school student learning in evolution: are current standards achieveable? Am Biol Teach. 2004;66:604-12.

Berkman MB, Pacheco JS, Plutzer E. Evolution and creationism in America's classrooms: a national portrait. PLoSBiol. 2008;6(5): e124. doi:10.1371/journal.pbio.00600124.

Bishop B, Anderson CW. Student conceptions of natural selection and its role in evolution. J Res Sci Teach. 1990;27:415-27.

Bloom P, Weisberg DS. Childhood origins of adult resistance to science. Science. 2007;316(5827):996-7.

Brazelton EW, Frandsen JC, McKown DB, Brown CD. Interaction of religion and science: development of a questionnaire and the results of its administration to undergraduates. Coll Stud J. 1999;33:623-8.

Chanet R, Lusignan F. Teaching evolution in primary schools: an example in French classrooms. Evol Educ Outreach. 2009;2:136- 40.

Colburn A, Henriques L. Clergy views on evolution, creationism, science, and religion. J Res Sci Teach. 2006;43:419-42.

Dagher ZR, Boujaoude S. Students' perceptions of the nature of evolutionary theory. Sci Educ. 2005;89:378-91.

Demastes SS, Settlage Jr JS, Good R. Students' conceptions of natural selection and its role in evolution: cases of replication and comparison. J Res Sci Teach. 1995;32:535-50.

Deniz H, Donnelly LA, Yilmaz I. Exploring the factors related to acceptance of evolutionary theory among Turkish preservice biology teachers: toward a more informative conceptual ecology for biological evolution. J Res Sci Teach. 2008;45:420-43.

Dodick J, Orion N. Geology as an historical science: its perception within science and the educational system. Sci Educ. 2003;12: 197-211.

Donnelly L, Akerson V (2008) High school biology students' evolution learning experiences. Paper presented at the annual meeting of the National Association for Research in Science Teaching, Baltimore, Maryland

Eldredge N, Eldredge G. Lessons from EEO: toward a universal evolutionary curriculum. Evol Educ Outreach. 2009;2:643-54.

Esbenshade Jr DH. Student perceptions about science and religion. Am Biol Teach. 1993;55:334-8.

Evans EM. The emergence of beliefs about the origins of species in school-age children. Merrill Palmer Q. 2000;46:221-54.

Evans EM. Cognitive and contextual factors in the emergence of diverse belief systems: creation versus evolution. Cogn Psychol. 2001;42:217-66.

Fail J. A no-holds-barred evolution curriculum for elementary and junior high school students. Evol Educ Outreach. 2008;1: 56-64.

Harris PL, Pasquini ES, Duke S, Asscher JJ, Pons F. Germs and angels: the role of testimony in young children's ontology. Dev Sci. 2006;9:76-96. 
Helgeson LJ, Hoover J, Sheehan J. Introducing preservice teachers to issues surrounding evolution and creationism via a mock trial. $\mathrm{J}$ Elementary Sci Educ. 2002;14(2):11-24.

Hermann RS. Evolution as a controversial issue: a review of instructional approaches. Sci Educ. 2008;17:1011-32.

Jensen MS, Finley FN. Teaching evolution using historical arguments in a conceptual change strategy. Sci Educ. 1995;72:14766.

Jensen MS, Finley FN. Teaching evolution using historically rich curriculum and paired problem solving instructional strategy. Am Biol Teach. 1997;59:208-12.

Johnston RL, Peeples EE. The role of scientific understanding in college; student acceptance of evolution. Am Biol Teach. 1987;49:93-7.

Lawson AE, Worsnop WA. Learning about evolution and rejecting a belief in special creation: effects of reflective reasoning skill, prior knowledge, prior belief and religious commitment. J Res Sci Teach. 1992;29:143-66.

Lombrozo T, Thanukos A, Weisberg M. The importance of understanding the nature of science for accepting evolution. Evol Educ Outreach. 2008;1:290-8.

Lord T, Marino S. How university students view the theory of evolution. J Coll Sci Teach. 1993;22:353-7.

Miller JD, Scott EC, Okamoto S. Public acceptance of evolution. Science. 2006;313:765-6.

Moore R. How well do biology teachers understand the legal issues associated with the teaching of evolution? Bioscience. 2004;54: $860-5$.
Moore R, Cotner S. Educational malpractice: the impact of including creationism in high school biology courses. Evol Educ Outreach. 2009;2:95-100.

Nadelson L, Culp R, Bunn S, Burkhart R, Shetlar R, Nixon K, Waldron J. Teaching evolution concepts to early elementary school students. Evol Educ Outreach. 2009;2:458-73.

Paz-y-Mino CG, Espinosa A. Assessment of biology majors' versus nonmajors' views of evolution, creationism, and intelligent design. Evol Educ Outreach. 2009;2:75-83.

Rutledge ML, Warden MA. Evolutionary theory, the nature of science and high school biology teachers: critical relationships. Am Biol Teach. 2000;62:123-31.

Sager C, editor. Voices of evolution. Berkeley: The National Center for Science Education, Inc.; 2008.

Scharmann LC. Enhancing an understanding of the premises of evolutionary theory: the influence of a diversified instructional strategy. Sch Sci Math. 1990;90:91-100.

Shtulman A. Qualitative differences between naïve and scientific theories of evolution. Cogn Psychol. 2006;52:170-94.

Sinatra GM, Southerland SA, McConaughy F, Demastes JW. Intentions and beliefs in students' understanding and acceptance of biological evolution. Journal of Research in Science Education. 2003;40:510-28.

Sinclair A, Pendarvis MP. Evolution vs. conservative religious beliefs: can biology instructors assist students with their dilemma? J Coll Sci Teach. 1997;27:167-70.

Wagler R. A missing link: K-4 biological evolution content standards. Evol Educ Outreach. 2010;3:443-50. 